\title{
Configurações
}

Revista de sociologia

\section{Compreendendo duas organizações - Escola de Enfermagem e Hospital - num contexto de supervisão de estágios}

Understanding two organizations: Nursing School and Hospital in a context of pratices supervision Comprendre deux organisations: École de Sciences Infirmière et l'Hôpital dans le cadre de supervision de stages

\section{Ana Paula Macedo}

\section{OpenEdition}

\section{Journals}

\section{Edição electrónica}

URL: http://journals.openedition.org/configuracoes/222

DOI: $10.4000 /$ configuracoes.222

ISSN: 2182-7419

\section{Editora}

Centro de Investigação em Ciências Sociais

Edição impressa

Data de publição: 30 Junho 2010

Paginação: 129-153

ISSN: 1646-5075

\section{Refêrencia eletrónica}

Ana Paula Macedo, "Compreendendo duas organizações - Escola de Enfermagem e Hospital - num contexto de supervisão de estágios », Configurações [Online], 7 | 2010, posto online no dia 18 fevereiro 2012, consultado o 22 abril 2019. URL : http://journals.openedition.org/configuracoes/222 ; DOI $10.4000 /$ configuracoes.222

Este documento foi criado de forma automática no dia 22 Abril 2019.

(c) CICS 


\section{Compreendendo duas organizações - Escola de Enfermagem e Hospital - num contexto de supervisão de estágios}

Understanding two organizations: Nursing School and Hospital in a context of pratices supervision

Comprendre deux organisations: École de Sciences Infirmière et l'Hôpital dans le cadre de supervision de stages

Ana Paula Macedo

\section{Introdução}

1 O interesse em comparar a Escola de Enfermagem e o Hospital inscreve-se, na actualidade, num quadro mais vasto que é o da caracterização da modernização -racionalização das actividades dos serviços. Nos dois sectores pressente -se um processo de modernização racionalização das actividades: a procura da qualidade total, a individualização da relação cliente -utilizador, a flexibilidade das estruturas, a racionalização dos recursos para se obter êxito e economizar os custos, a autonomia das organizações de base, entre outras.

2 Nestas duas organizações, igualmente, as transformações das actividades afectam os agentes beneficiários (alunos e doentes), prestadores de cuidados (professores e enfermeiros) que, para a maioria, exercem uma profissão que pode ser definida ao mesmo tempo como relacional e de semi -especialistas menos típicos (Etzioni, 1984: 119), caracterizada pelo status intermediário na sociedade e no lugar das políticas públicas.

3 A noção de relação, que está presente em algumas análises produzidas pela sociologia, pela economia e pela gestão, pode ser definida como uma interaç̧ão entre o prestador e um beneficiário, satisfazendo certas necessidades deste último em vez de uma mera prestação de serviço ${ }^{1}$. Sendo assim, a crítica que emerge à hipótese lançada de comparar a Escola (de Enfermagem) a um conjunto de serviços é que não é possível diferenciá -los 
claramente. As evoluções tendenciais (aumento da produtividade, individualização das prestações de cuidados, desenvolvimento da avaliação) não separam na totalidade o universo industrial do universo terciário. Neste caso, é importante distinguirmos uma racionalização industrial própria da produção de bens de uma racionalidade profi ssional própria dos serviços.

4 Para Demailly \& Dembinski (2002), cujas temáticas de estudo têm incidido nos modos de regulação e transformação dos sistemas de saúde, políticas públicas e grupos profissionais, há interesse em mostrar o carácter profundamente conflitual da noção de racionalidade económica. Os conflitos internos da racionalidade económica, como da racionalidade organizacional, estão presentes em vários sectores. A racionalização colocada em prática no universo industrial e terciário parece apresentar um fenómeno similar. Como notam ainda Demailly \& Dembinski, o lugar do neotaylorismo - a racionalização dos fl uxos (de papéis, de decisões, de informações, a centralização da informação nos poderosos sistemas informatizados, a intensificação do trabalho, a estandardização contínua dos procedimentos, os esforços da avaliação, as performances de cada um - faz emergir novos tipos de experts e novos tipos de cronómetros para medir o trabalho ${ }^{2}$.

5 Como destacam estes dois autores, a ideia de uma modernização-racionalização, funcionalmente contraditória, que concerne todas as organizações produtivas, industriais ou de serviços comerciais e não comerciais, parece originar a oferta de bens ou prestações, materiais ou relacionais. Se, por um lado, há uma aproximação da indústria aos serviços, nomeadamente a importância da fi gura do cliente como membro à parte de uma organização produtiva e a importância da gestão e do espírito gestionário ou do empreendorismo, por outro lado, as actividades de serviço aproximam -se da indústria; são alguns exemplos, a procura de economias de escala (tradicionalmente "inventadas" na indústria), compressão do "trabalho vivo" ao proveito das máquinas, organização de intensifi cação do trabalho.

6 É neste enquadramento que situamos as actuais políticas públicas de modernização e de reforma que integram frequentemente pressupostos, adoptam orientações e consagram soluções híbridas de tipo neotayloriano e de tipo "fordista" ou participativo (Messine, 1991; Lima, 1994). Foi tomando como enfoque estas soluções híbridas que procurámos analisar algumas dimensões organizacionais presentes na Escola de Enfermagem e no Hospital, em contexto de supervisão de estágios, procurando as articulações possíveis, tais como: compreender as lógicas de supervisão de estágios em enfermagem; caracterizar sociologicamente as articulações em contexto de acção concreta; contribuir para esclarecer alguns aspectos relativos ao contexto de trabalho hospitalar como local de formação e educação dos alunos estagiários de enfermagem.

\section{Escola de enfermagem e hospital - entre a ética e a economia}

7 A comparação entre a Escola de Enfermagem e o Hospital, como já referimos, torna -se pertinente pela representação particular deste tipo de organizações (pertencem à categoria das organizações produtivas de bens e de serviços), mas também pelas suas características específicas, que alguns pesquisadores e profissionais destas organizações têm vindo a referir. A simultaneidade da pertinência da noção da relação de serviço e do 
modelo gestionário -administrativo universal parece esmagar a especificidade das profissões relacionais do serviço público (educação, cuidado, trabalho social...) relativamente às actividades que têm como fim o mercado privado. Isto não significa que neste último se negue uma parte destas profissões e não possa ser analisada em termos de relação de serviços, actividade técnica, processos cognitivos ou mudanças comunicacio nais. Este exercício de proximidade parcial relevaria, certamente, paradigmas disciplinares ou escolhas epistemológicas diversas, tanto que admitiria o seu carácter redutor.

8 Como expusemos anteriormente, na esteira de Demailly \& Dembinski (2002), as actividades relacionais de serviço público parecem assumir uma configuração de racionalização idêntica à que existe nas actividades industriais, quer dizer, de uma racionalização económica contraditória e mista. São alguns exemplos as preocupações com a qualidade do serviço prestado e com a produtividade e/ou rentabilidade a curto termo, que conduz a economizar os custos, os empregos, o trabalho vivo. A sua especificidade é, portanto, na composição ético -política, ou mesmo essencialmente política, o que não deixa de ser interessante, uma vez que nas profissões de prestação de serviço esta especifi cidade parece ser negada. A prática profissional em matéria de saúde ou de educa-ção pública põe em jogo as orientações sociopolíticas, cujo debate fi ca aquém e além dos debates processuais e técnicos. Há concepções (de cidadania, de igualdade, de direito universal, etc.) que estão presentes na prática, ao nível colectivo, construindo os referenciais da acção pública ou os registos de legitimidade. Cada profissional de enfermagem, por exemplo, orienta a sua prática e estabelece uma relação de cuidados a partir de uma deontologia concreta. $\mathrm{O}$ mesmo acontece relativamente à ética pessoal: ela emerge de representações que renovam as concepções socioculturais e políticas da experiência dos cuidados. O trabalho de relação termina quando estão presentes valores e visões do mundo que permitem controlar as situações interaccionais com os doentes, mas também o trabalho com os outros membros do colectivo de trabalho (auxiliares de acção médica, fisioterapeutas, técnicos de análise e radiologistas, médicos internos, etc.).

Demailly \& Dembinski (2002) realçam que aquilo que será conjuntamente negado na vinculação de tais profissões à prestação de serviço é também a "terceira" dimensão, organizacional. Neste caso, a dimensão organizacional resiste à dimensão socioeconómica dos serviços, a qual não se deixa absorver num simples contrato (como livre acordo de vontade e de mudança) entre um prestador e um consumidor.

10 Neste ponto de vista, a Escola de Enfermagem e o Hospital são duas organizações que, ao transmitirem bens e serviços, são agentes legítimos da satisfação das necessidades humanas legítimas. Ao mesmo tempo, estas duas organizações definem as normas das necessidades que se supõe a população ter e ditam o bem moral e político para os seres humanos, individual e colectivamente. A educação e a saúde são questões inseparáveis da organização da nação. Governar e cuidar relevam então o mesmo princípio e obedecem às mesmas leis, o princípio da "Ciência do Homem" que deve percepcionar ou corrigir a natureza humana.

11 No decurso dos últimos anos, temos assistido, na maior parte dos países industrializados, a uma colecção de múltiplas modificações no seio de um sistema escolar, visando explicitamente uma reaproximação entre as organizações de formação profissional e o campo económico. Um trabalho explícito sobre o conteúdo da actividade educativa é realizado com o fi $\mathrm{m}$, diz -se, de assegurar uma grande adequação dos programas com as competências exigidas no trabalho. Esta procura de correspondência revela -se também 
nas formas de avaliação das actividades educativas, que se opera nas formas de transmissão pedagógica ou nas modalidades de avaliação. O Estado confia a novas instân cias a organização e estas articulações; instaura novos mecanismos de relação dos dois mundos, ou modifica a composição dos organismos existentes (novas fórmulas e arranjos institucionais), criando as condições de mediação dos interesses sociais e dando espaço aos actores económicos. Isto significa que, neste cenário, no caso do Ensino da Enfermagem, que é um exemplo da formação em alternância, desde o primeiro ano do Curso, a supervisão de estágios seria vista como articuladora dos dois mundos - Escola de Enfermagem e Hospital -, em que todas as intervenções atestam a existência de um processo onde se recompõem as relações entre formação e trabalho, sujeitas às pressões da efi cácia e da efi ciência e da produtividade.

As análises que enfatizam a leitura do tempo actual como uma confi guração particular de processos históricos de longo alcance parecem deter uma menor capacidade explicativa dos fenómenos e mutações com que não cessa-mos de nos confrontar. No caso das Escolas de Enfermagem, como de outros estabelecimentos do Ensino Superior, numa fase mais recente, aquelas têm sido induzidas a realizar uma avaliação de impacto sobre aquilo que ensinam, isto é, sobre o resultado da actuação da organização.

列entemente, a lei que aprova o Regime Jurídico das Instituições do Ensino Superior (Lei $n .{ }^{\circ}$ 62/2007, de 10 de Setembro) prevê a possibilidade de transformação de instituições públicas de Ensino Superior em fundações públicas de direito privado, parecendo privilegiar critérios de mercado com a finalidade de assegurar meios de auto subsistência, num quadro de progressiva redução do financiamento público. As mudanças na educação são multifacetadas e complexas; nas palavras de Stephen Ball (2004: 1115 -1116), os '“danos colaterais' de 'corporização', são parte da 'destruição criativa' do capitalismo, em que, nesse caso, os incentivos ao lucro e os valores dos negócios actuam para destruir os valores do serviço e a ética profi ssional".

14 No que diz respeito ao ensino de enfermagem, o quadro actual parece-nos intricado, devido à grande proliferação de escolas particulares, geradora de alguma mistura nos contextos de trabalho onde ocorrem os estágios e que permitem o acesso à profissão. Também o aumento do número de alunos nas escolas públicas e as mudanças verificadas no regime jurídico da gestão hospitalar têm gerado problemas objectivos e obstaculizantes à normal e tradicional articulação entre as escolas de enfermagem e as várias instituições de saúde.

Quanto ao hospital público, ele tem sido visto como indispensável para a análise do sistema de saúde, de acordo com as orientações políticas dominantes. O quotidiano do hospital fornece exemplos reiterados das escolhas éticas operadas tais como: a procura de transplantes, a experimentação com órgãos artificiais, os erros, as escolhas médicas em matéria de distribuição de moléculas custosas, que põem em causa as nossas representações culturais. Os discursos da responsabilidade (accountability), da melhoria, da qualidade e da efi ciência, que nos parece terem sido iniciados mais cedo no campo da saúde do que na educação, tornam as práticas existentes frágeis e indefensáveis - a mudança torna -se inevitável e irresistível, mais particularmente quando os incentivos estão vinculados às medidas de desempenho. Neste campo, também a performatividade desempenha um papel fundamental no conjunto das políticas (Ball, 2004: 1117).

O trabalho desta performatividade é complexo e simultaneamente pouco claro, porque se baseia na construção de um projecto de transparência. Isto é facilmente constatado, 
quando se observa as organizações do sector público a gastarem tempo, dinheiro e energia com a gestão das aparências, marketing e promoção.

É neste sentido que as orientações sociopolíticas, tanto ao nível macro das organizações e instituições, quanto ao nível micro das interacções quotidianas, incorporam a pertinência da comparação entre a Escola de Enfermagem e o Hospital.

Acrescentamos, todavia, uma precaução referente a este trabalho de comparação que é a seguinte: a extensão das transformações da organização do trabalho é variável segundo os subsectores, uma vez que a progressão da divisão do trabalho procede das tecnologias cognitivas, materiais ou imateriais. A formalização dos métodos, a estandardização dos actos, os recursos, os instrumentos e as infra -estruturas tecnológicas variam consoante se trate de um Centro Hospitalar Universitário ou de um Hospital público periférico, de uma Escola de Ensino Básico ou de um Colégio ou de uma Universidade. Isto significa que a comparação não pode ser feita à volta de denominadores comuns e de grandes tendências que se exprimem com mais ou menos força, segundo os casos.

\section{A evolução da escola de enfermagem e do hospital: da profissionalidade às políticas}

Dentro de uma nova ideologia do mundo global torna -se compreensível que os modelos que intentam captar a especificidade estrutural e funcional das organizações se alterem, desde logo porque as próprias organizações se instituem como um meio privilegiado de poder global. A proposta que é dada vai no sentido de se considerar que as organizações burocráticas não têm a agilidade e a flexibilidade necessárias para se confrontarem com o desafio da globalização (Estêvão, 2003: 87).

20 A modernização parece então desenvolver-se, sob a dupla contradição do neotaylorismo e da participação, ao nível organizacional, e da ética e da economia, ao nível político. Ela toca de forma conjunta as organizações, as profi ssionalidades e as políticas.

21 O trabalho dos profissionais relacionais de serviço público é actualmente confrontado com as exigências de mudança. Os seus empregadores incitam-nos para diversos caminhos (formação, culpabilização, reclamação por parte dos utentes do serviço público ou contribuintes) como forma de renunciar à referência artesanal sobre as quais estavam, frequentemente, pensadas as suas profissões, e passar a uma profissionalidade administrativa. Ao nível do discurso político, pretende -se que paralelamente se reúnam esforços de diversas áreas, capazes de gerarem uma nova e homogénea "cultura de enquadramento" e outras formas organizacionais.

22 No que concerne ao Hospital, a racionalização neoliberal depois dos anos 80 do século XX, afectou o conteúdo das actividades dos cuidados, até mais do que nas organizações de cuidados de saúde primários. No início dos anos 90, a racionalização neoliberal traduziu se em mudanças organizacionais neotaylorianas (racionalização dos percursos dos pacientes, centralização da informação, estandardização dos protocolos de cuidados, intensificação do trabalho, cronometragem dos "cuidados à tarefa" dos cuidadores, sectorização e planifi cação das actividades dos diferentes prestadores de cuidados) e mudanças do tipo participativo que visavam fazer passar uma lógica compatível com a actividade dos serviços e das patologias rentáveis, definidas a partir de uma negociação estratégica sobre a qual repousa o projecto de serviço médico e de enfermagem. 0 enquadramento dos cuidados, com supervisão por parte dos enfermeiros e dos chefes de 
serviço, é hoje considerado fundamental para a operacionalização e racionalização dos serviços. Muitas vezes, estes profissionais são incitados pelo alto enquadramento (directores da organização, enfermeiro director, enfermeiro supervisor, enfermeiroschefes, grupo coordenador da qualidade, entre outros) a uma efectiva supervisão dos cuidados. Há cerca de vinte anos que a totalidade destes agentes tem visto as suas missões, conteúdo e método de trabalho transformados. Isto acontece com outras equipas de trabalho do contexto hospitalar. Estes profissionais, também designados por parceiros da direç̧ão, são determinantes para a evolução da organização de trabalho. Eles têm por missão afastar projectos transversais (em matéria de equipamento e de orientação terapêutica) e dar soluções em função dos constrangimentos externos (exigências das tutelas, das agências regionais da hospitalização, concorrência com outras organizações), perspectivando a evolução da organização do trabalho. Algumas estratégias são concretizadas, tais como reuniões, grupos de projectos e formações em gestão planeadas pelos departamentos de formação que contribuem progressivamente para modifi car as práticas e os discursos destes novos parceiros da direcção.

No que se refere às políticas públicas e às desigualdades sociais, mais uma vez Lise Demailly e Olivier Dembinski encontram semelhanças entre a Escola (em geral) e o Hospital:

(...) as duas instituições parecem resignar-se num período recente a deixar de se produzir e se reproduzir, vendo o aumento das desigualdades sociais quanto aos acessos à educação ou ao cuidado, desigualdades que podem -se medir pelo que diz respeito à origem social dos públicos, mas também no que concerne o hospital às variáveis regionais. (Demailly \& Dembinski, 2002: 52)

Assim, dentro de um cenário cuja regulação se rege pelos princípios do mercado, a organização Escola adopta também por certas regulações do tipo mercantilista, nas quais os actores estão em concorrência (privado/público, boas/más, clássicas/profissionais) correlativamente a uma necessidade, tendo em vista a construção de uma clientela. Progressivamente, o mito da escola republicana que "fabrica" os cidadãos nacionais apaga -se, dando lugar à adaptação ao mercado de emprego, de acordo com as necessidades das famílias. As notas, os exames, as disciplinas tornam -se compatíveis com os coefi cientes de prestígio e de efi cácia escolar. Os estabelecimentos passam então a manter relações de concorrência a fim de agregar os melhores alunos, e tentam estabelecer uma reputação que lhes permita atrair os melhores públicos (jogo nas disciplinas opcionais, viagens, acções de comunicação, etc.). Deste modo, "a educação é, em vários sentidos, uma oportunidade de negócios” (Ball, 2004: 1108).

Da mesma maneira, no seio das organizações de cuidados em geral, e dos hospitais universitários em particular, um modelo profi ssional técnico -científi co, que caracteriza a elite hospitalar, hierarquiza-se numa relação comercial de concorrência onde as desclassificações são sinónimo de redução de actividade ou de despromoção. Os profissionais de saúde tentam lutar contra este "desvio", reafirmando, simultaneamente, as missões do hospital público enquanto centro de cuidados gratuitos e abertos à população próxima, tais como: oferecer os cuidados de primeira necessidade que reclamam por razões económicas, psicológicas, sociais ou médicas numa hospitalização; apreciar a gravidade dos casos tratados e reorientar os doentes, versus um serviço mais adaptado. Neste sentido, as críticas formuladas que vão ao encontro de uma medicina científi ca, produtivista e elitista podem ser travadas, mas não conseguem impedir o reagrupamento dos serviços impostos por facções hegemónicas dos médicos hospitalares e dos gestores hospitalares, que dão origem às desigualdades - regionais, de equipamentos e de acções 
nos cuidados. É neste quadro que se activa a designação dos "maus" doentes (não "rentáveis" ou com comportamentos indesejáveis), à semelhança dos "maus" alunos. As recentes audiências para a saúde parecem não trazer nada de admirável nas suas conclusões, mas põem em evidência dados, por vezes alarmantes, sobre certas facções da população e evocam sem rodeios a falta de efi cácia da política sanitária.

\section{Diferenças na "obrigação de resultados"?} efeitos da acção educativa, desde o seu início. Nesta sequência, a problemática da avaliação dos estabelecimentos de ensino e da acção pedagógica não pode ser separada da qualidade, da rentabilidade do serviço e da luta contra o insucesso escolar.

De mais a mais, um professor que admite a legitimidade da avaliação revolta -se a maior parte das vezes contra as formulações demasiado tecnicistas que reduzem a avaliação apenas aos resultados escolares: ele pensa na avaliação também em termos de socialização, desenvolvimento da curiosidade e do julgamento. (...) (Demailly \& Dembinski, 2002: 54)

Segundo Demailly \& Dembinski (2002), algumas razões podem explicar a resistência do corpo médico à ideia de uma luta contra o insucesso dos cuidados ou à ideia da qualidade total do serviço realizado, que visará a elevação do nível de saúde das populações do seu sector. Uma das razões é que os profissionais vêem esta ênfase como um signo de desprofi ssionalização. O status dos profissionais, muito divulgado na cultura norte -americana, está ligado à obrigação de meios: ter feito tudo para salvar da doença. Os hospitais uni versitários dispõem a este respeito de um arsenal de meios de investigação e de tratamento permanente para evitar o sentimento de culpabilidade face aos insucessos eventuais. Este facto permite -nos esta afirmação, pois no Hospital o domínio da técnica e da tecnologia constitui uma prioridade ${ }^{3}$. A tecnologia assume uma importância considerável e a sua utilização é gratifi cante quando há o salvamento de uma vida, como é o caso de uma paragem cardio-respiratória. A tecnologia pode permitir ao profi ssional satisfações imediatas e inadiáveis. Já não é o caso, quando a condição patológica do doente não necessita de tecnologias complexas. Certos insucessos introduzem por vezes a dúvida, mas o pensamento de uma maioria de profissionais da saúde é o de que a tecnologia deve permitir-lhes ultrapassar as dificuldades, reforçando ainda mais a sua mestria (ou domínio) das técnicas. Neste contexto, o erro pode -se tornar mais visível, porque a técnica chama a atenção para o problema de adequação, como por exemplo, um 
erro de laboratório, ou uma imagem dos exames auxiliares de diagnóstico que pode ser mais nítida. Ou seja, “(...) 'tudo a

fazer pela doença' é, sobretudo, 'não passar ao lado' (do diagnóstico). Aqui são necessários meios cada vez mais sofisticados e custosos, desenvolvidos e produzidos pela indústria". A lógica de mercado estimula a oferta de instrumentos médicos, cada vez mais pesados e especializados, de consumo de medicamentos, de actos médicos e de horas de máquinas.

Particularmente ajustada e adequada aos nossos tempos é a observação de Luís Martins, investigador da fiabilidade e da performance em organizações de saúde, a respeito da tecnologia médica nos hospitais:

A tecnologia prolonga as vidas, mas também tornou os profissionais e os doentes mais dependentes dela, durante o curso da doença crónica. A explosão tecnológica e os seus efeitos, quer na estrutura organizacional da prestação dos cuidados de saúde, quer no trabalho dos profissionais, produziram efeitos no tipo e na qualidade dos cuidados prestados ao doente. (Martins, 2005: 164)

Em jeito de síntese, ainda menciona:

(...) o aumento da especialização e a existência de estruturas de saúde burocráticas tiveram como efeitos a fragmentação da prestação de cuidados de saúde a doentes crónicos, o que aumenta as possibilidades de incidentes e de queixas de desumanização dos serviços. (Martins, 2005: 164)

Do nosso ponto de vista, a dominação do discurso técnico -gestionário, que privilegia as performances intrínsecas e os ganhos de produtividade directos, permite a abstracção de outras dimensões ligadas aos cuidados, (continuidade dos cuidados, observância, conforto e qualidade de vida, etc.), desvalorizando-se a pessoa/família e os profissionais de saúde. Isto, por sua vez, gera impacto social nos serviços de destino. Uma política de modernização dos serviços confi nados a uma redução das capacidades de acolhimento, dado o número elevado de cuidados, com uma aceleração de rotação dos pacientes poderá pôr em risco a credibilidade dos serviços prestados.

Se, para a Escola de Enfermagem, a obrigação de resultados tem o signifi cado de uma luta contra o insucesso, para o Hospital ela tem o signifi cado de uma luta contra o desperdício. A procura de uma melhor relação qualidade/ preço é imposta às organizações hospitalares como um meio de se afi rmarem sobre um mercado de cuidados. Os gestores de cuidados têm então tentado optimizar o par custo/produto: indicadores de cuidados de enfermagem, indicadores de encargos de trabalho, e ainda de outras funções alternativas à hospitalização, tais como, as redes de cuidados coordenados (que poderão ser um reagrupamento sob uma forma convencional de um Hospital ou de uma Clínica, um assegurador e uma empresa). Estas "comunidades de prática" e "redes de inovação" introduzidas pelas actuais reformas, cuja legislação aprovada sobre os hospitais, parcerias público -privadas, cuidados continuados e cui-dados de saúde primários, convergem todas elas no “(...) sentido da abertura do Serviço Nacional de Saúde aos grupos económicos e, por essa via, no sentido de transformá -lo num mercado de bens como outro qualquer" (Justo, 2005: 94). Esta inequívoca mudança de paradigma no sistema de prestação de cuidados em curso arrasta consigo outras tantas alterações no exercício das profi ssões e na gestão de cuidados, quer se trate do exercício no Serviço Nacional de Saúde, quer do exercício em Empresas de Saúde.

Esta excursão pela história de alguns desenvolvimentos nos quotidianos das organizações em estudo leva -nos a admitir que a Escola de Enfermagem parece estar potencialmente 
em vantagem sobre o Hospital ao manter-se afastada em termos de racionalização de mercado (no seio restrito ou rigoroso e não metafórico do termo mercado).

A questão que se coloca no nosso estudo relaciona -se com a compreensão da forma como esta deslocação é criada entre estas duas organizações, consideradas num contexto de supervisão de estágios.

\section{Metodologia do estudo}

O exercício de articulação entre a Escola de Enfermagem e o Hospital exige uma reflexão da nossa parte estimulada pelo estudo da supervisão de estágios, permitindo -nos esboçar, dentro de alguns limites, algumas semelhanças e diferenças entre as duas organizações. Uma análise $a$ priori às duas organizações parece apontar para uma evidência espontânea que as reaproxima em dois domínios, o dos cuidados e o da educação. Assim, a confrontação tem como objectivo identificar as articulações que temos posto em questão desde as suas origens. As perguntas orientadoras são as seguintes:

Será que a articulação entre Escola de Enfermagem e Hospital, ao ser reveladora das semelhanças/diferenças entre as duas organizações, favorece a supervisão de estágios?

Será que a articulação entre Escola de Enfermagem e Hospital favorece a integração dos alunos estagiários de enfermagem no contexto de trabalho hospitalar?

o percurso desta investigação foi o de entrelaçar algumas mudanças na supervisão de estágios com as mudanças sociais e políticas das organizações em estudo - Escola de Enfermagem e Hospital -, estabelecendo -se relações sociologicamente pertinentes entre ambas. $O$ estudo de pendor qualitativo e interpretativo destaca dois momentos empíricos: um, de triangulação de dados sobre os discursos e as práticas de supervisão de estágios, muito próximo dos actores, estruturando -se ao longo de um percurso investigativo considerável; e o outro, de intersecções entre a Escola de Enfermagem e o Hospital em contexto de supervisão de estágios. Considerando como objectivos primordiais: $i$ ) a identi ficação de modelos de análise da supervisão de estágios na articulação interor ganizacional entre a Escola de Enfermagem e o Hospital; ii) a caracterização da articulação interorganizacional entre a Escola de Enfermagem e o Hospital; e, ainda, iii) a compreensão das lógicas de supervisão de estágios de enfermagem, implícitas e explícitas, entre as duas organizações.

41 A abordagem de interesse heurístico que nos propomos fazer neste artigo, evidencia articulações relativas entre dois contextos organizacionais que se combinam num momento concreto - o estágio. Embora a amostra abranja mais actores convenientes para o estudo da articulação entre Escola e Hospital, para este artigo recorremos apenas aos actores intervenientes no momento do estágio de um curso de licenciatura em Enfermagem (amostra designada de oportunidade $e^{4}$ - oito alunos estagiários, cinco enfermeiros e a supervisora. A leitura dos dados recolhidos, através da análise documental (protocolos de articulação) e do inquérito por entrevista, é realizada a partir de uma grelha de análise que emergiu do quadro teórico -conceptual do estudo.

42 A metodologia de suporte ao estudo da articulação entre Escola de Enfermagem e Hospital em contexto de supervisão de estágio, enquanto objecto de investigação empírica, aproxima -se da investigação de tipo etnográfi co ou, para sermos mais sistemáticos, de um paradigma de investigação qualitativa, cujo método é um estudo de caso (Yin, 2005). 0 
período em que mantivemos a nossa presença assídua no contexto de estágio ocorreu nos meses de Janeiro e Fevereiro de 2007.

\section{0 contexto de supervisão de estágios}

43 A supervisão de estágios em enfermagem realiza -se necessariamente por referência, implícita ou explícita, às concepções ou representações organizacionais da Escola de Enfermagem e do Hospital. As práticas de supervisão em contexto hospitalar fi cam assim dependentes de uma hermenêutica organizacional, perseguindo as marcas teóricas que contextualizam e, sobretudo, conferem um certo sentido aos próprios processos de supervisão.

No ensaio metodológico realizado, que nos ajudou a direccionar a pesquisa empírica, intencionalmente fizemos cruzar algumas características organizacionais postas em evidência em diversos modelos de análise (cf. Ellström, 1983) com a proposta de Daniel Tanner e Laurel Tanner (1987) quanto à diferenciação entre dois modelos de supervisão ( $a$ supervisão como produção e a supervisão como processo de desenvolvimento), o que nos permitiu considerar outras formas de equacionar a supervisão de estágios em enfermagem.

A razão da nossa opção é que estes dois modelos são de alguma forma distintivos quando comparados, já que nos permitem completar a perspectiva científica e epistemológica da supervisão e sua relação e interdependência com os âmbitos didácticos e organizativos, além de contextualizarem a problemática da supervisão de estágios no contexto de trabalho hospitalar.

\subsection{Modelo de supervisão como produção em contexto de trabalho hospitalar}

46 A denominação deste modelo de supervisão indica claramente quais são os pressupostos conceptuais e as imagens com as quais se identifica. A concepção da organização como empresa e a adopção de modos de gestão científi ca e industrial são os alicerces sobre os quais se constrói um modelo de escola e de supervisão guiados por critérios de efi cácia e de efi ciência e rentabilidade. Estes critérios, ao serem aportados para a supervisão de estágios, passam pela determinação dos objectivos comportamentais específi cos, defi nidos operativamente, e do estabelecimento dos mecanismos de controlo capazes de medir o grau de cumprimento dos mesmos - controlo estabelecido. A crença na imitação para a estabilidade da prática (Tanner \& Tanner, 1980: 636) e na demonstração e imitação como a melhor maneira de aprender (Alarcão \& Tavares, 2003: 17 -18) são aspectos importantes para a sua definição. Complementarmente, a definição do conhecimento científico como a apreensão do objectivo, observável e medível, próprio da orientação científi co -racional, também conhecida como positivista e empirista, é de suma importância para se compreender este modelo de supervisão. Se pensarmos no Hospital, lugar onde acontece a supervisão de estágios em enfermagem, dentro desta linha de pensamento, parece haver, também, uma proximidade à organização segundo o modelo racional -burocrático de Per-Erik Ellström (1983), cuja estrutura é constituída em grande parte por órgãos (departamentos, serviços) e respectivas funções (Hall, 1984: 230).

Uma das primeiras apreciações que nos apraz fazer às elocuções dos actores entrevistados 5, no que diz respeito à dimensão "Hospital como Organização", é que estas continham 
elementos que poderíamos remeter para o modelo racional-burocrático e, curiosamente, apontavam -nos para as dimensões de supervisão dentro do modelo de supervisão como produção.

A este propósito, dois dos entrevistados associaram a complexidade do Hospital ao facto de nele poder existir uma hierarquia complexa, caracterizada por funções e poderes muito diferenciados:

É uma instituição bastante complexa, com níveis hierárquicos bastante ins titucionalizados e que tem como objectivo final a prestação de cuidados de saúde nas diferentes áreas. (Est. 8)

Já para Etzioni (1974), o termo "organização complexa" tinha o significado de "organização complexa burocrática", predominantemente normativa, caracterizada por uma hierarquia e por profissionais que desenvolvem funções distintas de grupo para grupo.

O Hospital é uma organização onde se prestam cuidados de saúde e surge muitas vezes referenciado por possuir várias valências de especialidade. Por isso, esta organização também surge associada à imagem de Hospital como organização multidisciplinar e, simultaneamente, como local de ensino:

Nele trabalham muitos profissionais mais ou menos relacionados com a saúde: médicos, enfermeiros, auxiliares de acção médica e técnicos tais como: radiologistas, farmacêuticos, psicólogos, mas também outros profi ssionais ligados à manutenção de toda a estrutura e gestão hospitalar (...). É também um local de ensino, pois estabelece parcerias com diferentes escolas. (Est. 3)

51 Em consonância com o enunciado anterioremente, o Hospital enquanto empresa surge assim representado por alguns entrevistados. Quase sempre esses discursos enfatizam a efi ciência e a produtividade organizacional (máximo rendimento pelo menor custo, ganhos em saúde), pela importância de se responder às necessidades de saúde através da prestação de serviços que devem satisfazer os (agora) clientes:

Pode também dizer-se que o Hospital é uma empresa, pois envolve a gestão de dinheiro para que possa subsistir. (Est. 3)

Penso que estamos a caminhar para o Hospital tipo empresa, temos vindo a assistir a uma focalização economicista, a parte humana tem vindo a ser desvalorizada. (Enf. 5)

Quanto aos objectivos e preferências da organização hospitalar, parece existir uma uniformidade de respostas por parte dos alunos estagiários. Tendo em conta a especificidade da organização hospitalar, muitos entrevistados referem que:

O objectivo é fornecer cuidados de saúde (tratamento, informação e orientação) à população. Mas nem todos os actores têm competência para cumprir tais objectivos. (Est. 2)

O objectivo máximo do Hospital é prestar cuidados de saúde a quem a ele recorre, tendo como base a promoção da qualidade de vida. Estes objectivos devem ser cumpridos por todos os actores do Hospital. (Est. 4)

53 Já o grupo de enfermeiros entrevistados, na sua maioria, posicionou -se de imediato numa perspectiva gerencialista, ao referirem -se aos objectivos do Hospital. Repare -se que há uma tendência para naturalizar um certo número de palavras ou mesmo expressões nos discursos dos entrevistados, tais como "cliente" (em vez de doente), "qualidade", "excelência dos cuidados":

Os objectivos do Hospital são a prestação de cuidados com qualidade. (Enf. 2)

A finalidade única é prestar cuidados de qualidade através de profi ssionais competentes, para satisfazer as necessidades dos clientes. (Enf. 3) 
Os actores estão inseridos numa fi losofia de cuidados - a prestação de cuidados de saúde, atendendo à excelência dos cuidados. Por isso necessitam da acreditação, de aprimorar todos os actos para a excelência. (Sup.)

Um aspecto interessante deste último excerto é o facto de nele se dar ênfase aos aspectos que visam a aproximação dos actores à fi losofia e à meta organizacional que se pretende atingir "[...] em princípio os objectivos deveriam servir todos os actores". Esta visão inclina -se para uma aproximação entre os objectivos da organização e os interesses e preferências dos actores organizacionais. Ora, sabemos que há uma tendência actual, principalmente em grandes organizações, para acentuar nas pessoas modos de ser que favoreçam a fácil inserção no meio social das organizações. Desta forma, favorece -se a aceitação de indivíduos que sejam facilmente adaptáveis à inserção em grupos diversos, fazendo coincidir as suas motivações ou as suas aspirações de sucesso com os perfi s de carreira dentro das organizações (cf. Etzioni, 1984: 146).

5 Numa grande parte dos discursos em que o Hospital é visto como uma empresa, encontramos alguns aspectos comuns ao modelo racional -burocrático, ou seja, alguns dos actores parecem aceitar que os objectivos são claros e que o consenso é partilhado. Mas também encontramos em alguns discursos contradições ou desconexões, relativamente ao que acabámos de referir e o que seria de esperar numa organização hierárquica.

Numa organização definida como burocrática, as tecnologias são claras e os processos de decisão e de planeamento são estáveis. A existência de normas e regulamentos que fixam cada "área de jurisdição", além de facilitar os processos de decisão, permite também o controlo da continuidade dos cuidados, a uniformidade e a previsibilidade de comportamentos por parte dos profi ssionais que trabalham num Hospital.

Os alunos estagiários referem isso mesmo:

Servem para estabelecer prioridades, estabelecer protocolos e para organizar todo um serviço, e penso que elas são na sua maioria cumpridas. (Est. 1)

As normas servem para 'impor regras' que devem ser por todos respeitadas, visam padronizar determinados procedimentos para que todos os utilizadores do Hospital vejam as coisas do mesmo modo. (Est. 7)

58 Numa lógica gerencial, em que se institui uma fi losofia de gestão para que se alcance a produtividade, os profissionais aparecem como estando mais conscientes do cumprimento das normas. É o que dá a entender a próxima entrevistada:

O papel das normas no Hospital é uniformizar os cuidados para no fi nal existir uma maior produtividade. Claro que muitas vezes há fugas ou por desconhecimento, ou porque dá mais jeito contornar determinada situação, mas com as auditorias o cumprimento das normas tem de ser mais rigoroso. Os profi ssionais estão mais conscientes de que têm que cumprir as normas e tentam cumprir com medo de serem chamados a atenção por causa das auditorias. (Enf. 5)

59 Neste caso, as tecnologias/processos são consideradas como qualquer técnica que uma organização utiliza para efectuar o seu trabalho e surgem associadas ao controlo da qualidade, não só da "matéria -prima" como também dos profissionais que lá trabalham, além de orientar para os objectivos da organização. As "normas e os critérios de qualidade", que todos os serviços do Hospital possuem, até podem ter essa função.

Um outro aspecto importante, ligado aos processos decisionais dentro da organização hospitalar é a autonomia dos profissionais. A autonomia no contexto de trabalho hospitalar, em sentido restrito, refere -se à liberdade no exercício das funções e na realização das actividades. No entanto, optamos por considerar um sentido mais abrangente, isto é, entendendo a autonomia neste contexto como um espaço de 
intervenção nos processos de trabalho, onde é possível o autocontrolo e a auto -avaliação e, ainda, a participação na organização, bem como a oportunidade de influenciar as decisões na organização do trabalho e nas condições em geral. No quadro do modelo racional -burocrático do Hospital como organização, a autonomia dos profissionais parece ter algumas especificidades. Por exemplo, numa organização como o Hospital, os pro fissionais procuram novas formas de poder e as normas muitas vezes são um dos meios que os enfermeiros têm para demonstrar a sua autonomia:

Eu considero que as normas não são inibitórias da autonomia profi ssional, eu até acho que permitem uma maior autonomia profissional. As estratégias e os princípios descritos nos procedimentos, nas políticas, etc. têm implicitamente e explicitamente representada a voz dos enfermeiros. (Enf. 3)

Também a autonomia dos profissionais no Hospital está muito associada à delegação de cuidados e ao poder atribuído ao especialista:

No nosso quotidiano podemos ser gestores de cuidados, quando gerimos recursos humanos ou rentabilizamos recursos. A supervisão implica uma delegação de cuidados, não sei se bem fundamentada. A supervisão acontece quando delegamos alguns procedimentos às auxiliares de acção médica. (Enf. 3)

$\mathrm{Na}$ actual mudança produzida pelas tecnologias de informação e comunicação, consideradas forças que modelam as relações sociais, económicas e políticas nas organizações e na sociedade em geral, há quem preveja um panorama diferente, de algum modo pessimista, para os profissionais de saúde, como nos diz a próxima entrevistada:

Parece -me que a polivalência vai prevalecer em desfavor da especialização. Os profi ssionais terão que dominar diferentes áreas de especialização. Penso que também a supervisão vai ser transformada, figuras de supervisão que sejam caras serão para abater. O predomínio será o saber-fazer. Aí talvez a enfermagem possa perder ou regredir na sua autonomia. (Enf. 2)

Nesta óptica, enquanto as novas tecnologias levam à "generalização do trabalho inteligente", mais complexo, mais flexível, de relações de parceria, exigindo conhecimentos mais amplos e de autonomia, iniciativa, responsabilidade, criatividade, capacidade de aprendizagem contínua e autocontrolo, simultaneamente parece existir o reforço dos princípios tayloristas e do controlo e, por conseguinte, a redução da autonomia no trabalho (Kovács, 2006: 42).

As percepções sobre supervisão, a partir dos intervenientes deste estudo de caso, revelam uma vinculação a algumas dimensões do modelo de supervisão como produção. A definição do conhecimento científico como a apreensão do objectivo, observável e medível, próprio da orientação científi co -racional, também conhecida como positivista e empirista, é de suma importância para se compreender este modelo de supervisão:

A supervisão para mim é o conhecimento pleno de determinada área ou segmento. Considero que é importante para os alunos serem acompanhados, como ainda não são profissionais têm que ter alguém responsável que responda por eles. (Enf. 1)

A supervisão para mim... penso que se relaciona com funções de coordenação, de planeamento, de controlo e de avaliação das actividades profi ssionais, educativas etc. (Enf. 2)

No que diz respeito aos testemunhos dos alunos estagiários, cinco das suas concepções de supervisão são reveladoras de uma concepção tradicional de supervisão. Os conceitos, na sua maioria, parecem -nos conotados com a origem da supervisão e o seu primeiro significado na organização do trabalho industrial, nos moldes taylorista -fordista.

Vigiar o progresso de alguém, corrigir, criticar, orientar. (Est. 1) 
É processar optimizar o rendimento através da intervenção e assistência ao executante.(Est. 2)

A supervisão para mim é assistir, vigiar o processo de alguém ou alguma coisa, o que inclui avaliar, corrigir determinada actividade. (Est. 4)

Nesta dimensão, a formação em contexto de estágio insiste sobre as regras e os procedimentos, sendo organizada em função dos resultados mensuráveis e avaliáveis, cuja obtenção pretende garantir um nível definido de competências em termos de conhecimentos, de comportamentos, de actuações e de habilidades. Assim, a capacidade de iniciativa e de intervenção do aluno estagiário em formação, com vista a melhorar as condições de realização do trabalho, tende a ser desvalorizada.

67 A formação fica então reduzida à aprendizagem, na sua acepção restrita, excluindo do seu campo novas formas de pensamento e não procurando deliberadamente modificações dos formandos (Ferry, 1991: 70). Se, por um lado, o lugar do saber se situa essencialmente no supervisor (formador/especialista), o que conduz a uma relação assimétrica entre supervisor e alunos estagiários (Lesne, 1984: 47 -48); por outro lado, o supervisor é um elemento mais da cadeia de montagem, sem nenhum tipo de competência autónoma no seu trabalho, quando muito ocupando -se em aplicar testes e grelhas quantificadas para medir os resultados. Por exemplo, a introdução de práticas pedagógicas inovadoras nos estágios é vista como um problema, conforme surge realçado nos discursos de alguns entrevistados supervisores:

Há quase sempre uma subjugação da Escola ao Hospital, eu não sou livre de desviar o aluno do processo de cuidados, tenho que estar sempre sujeita à dinâmica de cuidados, atenta ao que está a acontecer. Depois também não há espaços físicos para reflectirmos em conjunto. $O$ aluno está quase sempre em tensão (...). (Sup.)

68 A maioria dos discursos indicia a existência de uma grande responsabilidade por parte do aluno estagiário na adaptação às actividades em contexto de trabalho, onde o imprevisível acontece e onde o tempo da execução da tarefa time -on -task se torna um problema consciencializado por eles:

Hoje o dia foi mais intenso, hoje já tivemos de administrar a terapêutica e já tive mais acções de enfermagem. A gestão do tempo torna -se mais difícil. É um aspecto que me preocupa - gerir o tempo. Quando for profissional, vou cuidar de pelo menos cinco doentes, no mínimo, como é que eu vou conseguir gerir o tempo? Bem sei que, com a experiência, vou adquirindo maior destreza e vou planeando melhor as minhas acções. (Est. 6)

Relativamente à análise das estratégias de supervisão, alguns depoimentos denunciam formas de pensamento e lógicas que poderão, na nossa opinião, constituir uma ameaça à autonomia dos futuros profissionais de enfermagem, quando se trata de encorajar os alunos estagiários a aprendizagens solitárias e a aplicação de dispositivos padronizados.

\subsection{Modelo de supervisão como processo de desenvolvimento em contexto de trabalho hospitalar}

O modelo de supervisão como processo de desenvolvimento pretende ser uma proposta superadora das deficiências e limitações que apresentava a supervisão como produção de Tanner \& Tanner (1987). Aqui a pessoa em formação adquire uma posição diferente do modelo precedente, não é um agente de distribuição da instrução que leva a cabo para fi ns prefixados de um curriculum estabelecido por uma fonte de autoridade externa, mas faz parte como elemento activo dos processos de resolução. Estamos dentro de uma outra 
perspectiva prática e emancipatória de inter-relação dos diversos contextos de decisão. Neste caso, a supervisão é em boa medida influenciada pela perspectiva bron fenbrenneriana, em que os profissionais se vão inserindo num conjunto articulado de microssistemas. Estes, para além de interagirem entre si, integram -se em redes estruturais mais complexas, designadas por meso e macrossistemas, que indirectamente exercem sobre a pessoa em formação uma enorme infl uência (Alarcão \& Tavares, 2003: 38). Nesta abordagem, não deverão ser descurados outros modelos organizacionais alternativos, como o modelo político e o modelo anárquico, apresentados por Per-Erik Ellström (1983).

71 Considerando as dimensões de análise do modelo de supervisão como processo de desenvolvimento, é conveniente realçar que a evidência de alguns elementos dentro da dimensão "Hospital como organização" (tais como: os objectivos, as tecnologias e os processos ), se vai tornando escassa à medida que avançamos na análise a partir do modelo político $e$ do modelo anárquico. Apenas três dos entrevistados olham para a organização hospitalar como um lugar onde surgem conflitos de interesses e a consequente luta pelo poder entre os diferentes grupos socioprofissionais e dentro da mesma profissão, como nos diz o seguinte excerto de entrevista:

Por vezes penso que existe um conflito de interesses. Denota -se um pouco de rivalidade entre elementos de profissões distintas e mesmo dentro de cada profi ssão. (Est. 5)

72 As falas de alguns actores deixam transparecer também que as decisões dentro da organização hospitalar se baseiam no poder e na influência dos diversos indivíduos e grupos, desenrolando -se basicamente a partir de processos que visam atingir os seus interesses. Deste modo, as metas organizacionais tornam-se ambíguas e sujeitas a interpretações políticas nem sempre coincidentes.

73 Se à partida os objectivos organizacionais são comuns a todos os profi ssionais - a prestação de cuidados de saúde -, na implementação desses objectivos já não parece ser assim: os indivíduos, os grupos de interesse e as coligações têm os seus próprios propósitos e actuam para os alcançar. Dentro desta arena política, onde acontecem as decisões importantes que supõem ou implicam a distribuição de recursos escassos, uns são mais beneficiados do que outros. Como refere a supervisora de estágio,

O conflito de interesses, claro que existe, há beneficiados, há prejudicados. Os actores que tentam impor o consenso são aqueles que têm mais a perder, as chefi as intermédias tentam quase sempre fazê -lo. (Sup.)

No modelo político, os actores mobilizam estrategicamente os seus recursos de poder no sentido de reconverter os seus valores e metas em infl uência efectiva. Neste sentido, as tecnologias/processos utilizados tendem a ser transparentes e claros. Apenas uma entrevistada focou um aspecto importante, relativo a este elemento de análise, considerando que são, muitas vezes, as tecnologias e os processos as principais fontes de confl ito dentro da organização hospitalar:

Nem sempre as normas são rigorosamente cumpridas. Há sempre discórdia entre os profi ssionais, pelos quadros de referência que têm. (Sup.)

Procuramos também nos discursos dimensões do modelo anárquico. As possibilidades tradicionais de avaliar as consequências de uma decisão e de as relacionar com objectivos, ou de consignar simplesmente um efeito a uma causa, deixam de existir ou quase não existem no modelo anárquico. 
76 Recordamos que os modelos ambíguos consideram a estrutura organizativa como problemática por estar sujeita a mudanças. Karl Weick (1995) descreveu seis eixos analíticos básicos que se encontram em novas defi nições sobre "o que é uma organização?", e que serviriam para construir uma alternativa ao modelo burocrático de Weber. Esses eixos seriam os seguintes: “i) há menos racionalidade do que se vê; ii) as organizações são segmentadas mais do que monolíticas; iii) os segmentos estáveis nas organizações são bem pequenos; iv) as conexões entre segmentos têm uma força variável e produzem ambiguidade; v) as conexões de força constante reduzem a ambiguidade" (cf. Borrel Felip, 1989: 123 -124).

Algumas passagens dos discursos dos actores sugerem a presença de algumas dimensões do modelo anárquico:

Vejo o Hospital como um local de trabalho, no qual se exige uma dedicação e uma actuação constantes a novas situações, nada é um continuum. Há uma mutação permanente dentro do Hospital. Noutras actividades profi ssionais é possível organizarem -se rotinas; as diferentes profissões que trabalham num Hospital difi cilmente conseguem estabelecer rotinas. (Enf. 3)

Existem normas com dificuldades de serem cumpridas, são normas absurdas perante a nossa realidade. (Enf. 5)

A aproximação do aluno estagiário ao contexto de trabalho, às políticas e acções não se encontra, nos seus aspectos fundamentais, na dimensão formal, ou nos seus objectivos declarados, mas a partir de "milhares de processos subterrâneos dos grupos informais" (Perrow, 1990: 53).

$79 \mathrm{Na}$ análise aos discursos dos alunos estagiários acerca do trabalho verifi camos que estes se baseiam em representações colectivas diferentes, que constroem a partir do sistema social da organização, designadamente: formas de identificação com os pares, com os chefes, com outros grupos profi ssionais, com valores fundamentais de um determinado contexto. Ao contrário da defi nição de identidade que deriva da perspectiva biográfi ca, a defi nição salientada nos discursos situa a identidade na "experiência relacional e social do poder", onde as relações de trabalho permitem experiências de confronto dos desejos de reconhecimento, num contexto de acessos desiguais e complexos. Trata -se, portanto, de uma transacção objectivamente verificável na análise das situações de trabalho e dos sistemas sociais da organização.

80 Neste contexto, a supervisão centra -se na sensibilização de aspectos importantes para a formação dos futuros enfermeiros e para os tornar mais "autónomos e responsáveis". Encontramos nos testemunhos de dois entrevistados uma visão de supervisão facilitadora do desenvolvimento de conhecimentos (por recurso à reflexão), de habilidades técnicas e de aprendizagens colectivas (assentes em valores e princípios democráticos), originária do envolvimento e da responsabilidade, promovendo, assim, a autonomia profi ssional:

A supervisão é para mim: um conjunto de competências que o formador deve adquirir, para promover nos alunos aprendizagens. Orienta, gera, treina, permite o pensamento crítico, partilha de informações, aquisição de novas experiências segundo os contextos. (Sup.)

Na minha opinião a supervisão consiste na presença de um profi ssional competente na sua função, bem como portador de determinadas qualidades humanas, durante o processo de aprendizagem. Este deverá acompanhar, participar e interagir com os aprendizes para que haja um bom processo de aprendizagem. (Est. 6)

81 O próximo depoimento, de um aluno estagiário, refere -se a um tipo de acompanhamento e a uma atitude do supervisor, que poderemos considerar que têm algumas características 
que se aproximam deste modelo de supervisão - supervisão como processo de desenvolvimento:

Aprecio um acompanhamento tipo liberal, na medida em que podemos tomar iniciativa e participar nas actividades, mas sempre com o apoio, a supervisão e a orientação do professor. Considero que são importantes os espaços de reflexão e discussão acerca das matérias que abordámos na prática de cuidados. Como também considero que é importante a aposta na qualidade dos orientadores de estágio em termos teóricos e práticos, mas também no número de horas de acompanhamento. (Est. 2)

Outros discursos dão -nos marginalmente a perceber uma ampliação da formação dos alunos estagiários ocorrida em consequência da experiência de estágio e que vai para além do curriculum estabelecido, ou que se previa que viesse a acontecer em determinada unidade de cuidados.

Razões de clareza da aplicação do nosso quadro teórico levaram -nos a distinguir diferentes estratégias de supervisão interactivas e de diferentes estilos, que vão dando origem a reconfi gurações específicas nos diversos espaços de aprendizagem, dentro de um horizonte temporal, onde a dinâmica de construção dos actores sociais na e pela socialização está presente. Nesta dimensão de análise destacamos dois depoimentos que valorizam algumas estratégias que se geram no colectivo e no empenhamento autoformativo. Estas estratégias são capazes de desenvolver a autonomia do aluno estagiário e, por outro lado, do próprio supervisor.

Uma das modalidades que poderá constituir formas de supervisão é, por exemplo, a análise de casos. (Sup.)

Uma forma de supervisão com vista à análise da prática de cuidados pode passar pela realização de debates sobre situações ou casos vividos em contexto de estágio. (Est. 7) em se implementarem algumas mudanças na supervisão de estágios, propondo como solução a constituição de grupos de discussão e "de partilha, com dinamizadores com uma visão de fora", dando a entender que tal iniciativa deveria partir do grupo de professores da Escola de Enfermagem:

Algumas estratégias seriam fabulosas se nos pudéssemos desviar, por alguns momentos, da prestação de cuidados e reflectíssemos em conjunto... A partir da admissão do doente naquele serviço o banho é diário. Vamos então pensar: porque é que aquele doente precisa de um banho? Porque é que não temos esse género de atitudes? A mudança passa pela formação de professores na dimensão pedagó-gica e crítica, na linha de Paulo Freire. Seria importante fazer-se uma avaliação da avaliação. Uma das estratégias seria proporcionar aos professores a organização de grupos de partilha, com dinamizadores com uma visão de fora. (Sup.)

\section{Conclusões}

Podemos, pois, concluir que a análise de práticas que fazem parte do contexto de estágio hospitalar, enquanto estratégias de supervisão para o desenvolvimento, e de acordo com alguns depoimentos, parece ainda estar afastada da realidade concreta da supervisão. A análise de práticas, enquanto estratégias de supervisão para o desenvolvimento, remete, pois, para domínios que são fundamentais estarem presentes (os percursos pessoais, os contextos socioculturais, os grupos de vida, os constrangimentos organizacionais, as expectativas, os projectos, as frustrações) e serem discutidos por todos os actores que se 
intersectam nos estágios. Como diria José Alberto Correia (1999: 64), a abordagem das práticas profissionais passa pelo “(...) reconhecimento do que se tornou significativo, das condições de significação, das relações interactivas que favorecem a emergência das situações formativas, ou que, pelo contrário, as negam ou limitam".

Se olharmos para os aspectos organizacionais atrás referenciados, parece-nos ter alguma capacidade hermenêutica o modelo de supervisão como desenvolvimento, dado ser este que considera o nível meso e macro, superando dualismos na gestão do ensino (Escola de Enfermagem) e na instituição onde o estágio ocorre (Hospital), aparecendo em ambos como um espaço de confl uência de distintas dimensões de outros modelos analisados. A complexidade do exercício metodológico implícito ao estudo parece estar na "arrumação" dessas mesmas dimensões, retirando alguma centralidade explicativa ao modelo de supervisão como produção, apesar de este ser hoje grandemente dominante. Embora muitas das tentativas da gestão da crise apontem para uma possível articulação entre os dois modelos, não cremos ser viável a sua compatibilização, sobretudo quando considerados determinados valores e orientações em termos de formação e de actividade profissional. Se, por um lado, as duas organizações (Escola de Enfermagem e Hospital) onde acontece a supervisão de estágios, parecem balançar na defesa de valores humanísticos e de autonomia de signo democrático e participativo, por outro lado, esses mesmos valores deixam de fazer sentido, e até são difíceis de conciliar, quando se pretende a introdução de outras lógicas emergentes, como sejam, a da efi ciência, a da eficácia e a da produtividade.

Retomando a ideia acima referida, os discursos dos actores apontam com maior evidência para uma aproximação da organização hospitalar a um modelo racional -burocrático com dimensões de cariz gerencialista e empresarial e, implicitamente, os valores da eficácia, da eficiência e da produtividade tornam -se mais evidentes, relativamente à Escola de Enfermagem. Esta particularidade é às vezes referida como se estivéssemos na presença de um status antropológico diferente atribuído às duas organizações em causa. Para a Escola de Enfermagem, a obrigação de resultados tem o significado de uma luta contra o insucesso; para o Hospital ela tem o significado de uma luta contra o desperdício. No entanto, face à pluralidade e ao eventual antagonismo entre os pontos de vista dos actores envolvidos e entre as orientações e as acções praticadas, dificilmente poderíamos considerar como modelo único a ser analisado. Aliás, como pudemos constatar num anterior estudo, relativo à organização hospitalar e à formação nesse contexto, outras dimensões de análise estão presentes, como as dimensões do modelo anárquico, embora não transpareçam tão facilmente do discurso dos entrevistados, por serem tão fluidas e por isso tão pouco perceptíveis e difíceis de apreender.

Tendo como pano de fundo o quadro prospectivo traçado, a Escola de Enfermagem está potencialmente em maior vantagem sobre o Hospital, ao manter-se afastada em termos de racionalização de mercado. Talvez a manutenção deste estado de resistência seja possível, desde que a Escola de Enfermagem adopte uma nova perspectiva de formação e investigação (crítica) que permita uma outra maneira de olhar a realidade dos contextos de trabalho, criando novos "pontos de entrada" investigativa. Não está aqui em causa o aparecimento de mais um objecto de estudo em enfermagem, numa lógica de mera adição, mas sim a emergência de uma nova perspectiva de investigação que tenha em con sideração no seu ensino as vertentes organizacionais. Por exemplo, as questões colocadas no interior de uma área específica, como é, neste caso, a supervisão de estágios em enfermagem, ao equacionarem os contextos onde ela ocorre e os actores que dela fazem parte (alunos estagiários, professores e enfermeiros), poderão conduzir à aproximação de 
uma concepção alargada de supervisão, tornando possível a articulação interorganizacional entre Escola e Hospital.

O que nós retemos finalmente desta comparação é o papel decisivo dos actores colectivos, profissionais (professores e enfermeiros) e agentes benefi ciários (alunos e doentes) que necessitam de cuidados, no funcionamento futuro destas grandes organizações.

\section{BIBLIOGRAPHY}

ALARCÃO, Isabel \& TAVARES, José (2003), Supervisão da Prática Pedagógica - Uma perspectiva de desenvolvimento e de aprendizagem na formação de professores, Coimbra, Almedina.

BALL, Stephen (2004), "Performatividade, privatização e o pós -estado do bem -estar", Educação e Sociedade, Campinas, vol. 25, n.. 89, Setembro/Dezembro, 1105 -1126.

BLAU, Peter \& SCOTT, Richard (1977), Organizações Formais, São Paulo, Atlas.

BORRELL FELIP, Nuria (1989), Organización Escolar. Teoría sobre las Corrientes Científicas, Barcelona, Humanitas.

CORREIA, José (1999), Formação de Professores: Da racionalidade instrumental à acção comunicacional. Lisboa, Edições Asa.

DEMAILLY, Lise \& DEMBINSKI, Oliver (2002), "La réorganisation managériale à l'école et à l'hôpital", Éducation et sociétés, n.․ 6, 43 -64.

ELLSTRÖM, Per-Erik (1983), "Four faces of educational organizations", Higher Education, n.. 12, 231 $-241$.

ESTÊVÃO, Carlos (2003), "Fragmentos de globalização na administração da educação e o lugar da escola nas políticas educativas globais", Cadernos de Ciências Sociais, n.ำ 23, 83 -100.

ETZIONI, Amitai (1984), Organizações Modernas, São Paulo, Livraria Pioneira.

FERRY, Gilles (1991), El Trayecto de la Formación: los Enseñantes entre la Teoría y la Práctica, Barcelona, Paidós Educador.

HALL, Richard (1984), Organizações, Estruturas e Processos, Rio de Janeiro, Prentice -Hall.

JUSTO, Cipriano (2005), Mudar, para Onde, com Quem e Porquê, Lisboa, Campo da Comunicação.

LESNE, Marcel (1984), Trabalho Pedagógico e Formação de Adultos, Lisboa, Fundação Calouste Gulbenkian.

LIMA, Licínio (1994), “Modernização, racionalização e optimização. Perspectivas neo -taylorianas na organização e administração da Educação", Cadernos de Ciências Sociais, n.ำ 14, 119 -139.

MARTINS, Luís (2005), “O erro como periferia do sistema: do ciclo da culpa à mudança organiza cional, nas organizações de saúde”, in J. Fragata \& L. Martins; C. Borges \& P. Martins (orgs.), 0 Erro em Medicina. Perspectivas do indivíduo, da organização e da sociedade. Coimbra, Almedina, 147 $-211$. 
MESSINE, Philippe. (1991), Os Saturnianos. Quando os patrões reinventam a sociedade, Lisboa, Edições Sagres - Promontório.

PERROW, Charles (1965), "Hospitals: Technology, structure, and goals", in J. March, Handbook of Organizations. Chicago, Rand McNally \& Company Chicago, 910 -971.

PERROW, Charles (1990), Sociologia de las Organizaciones, Madrid, McGraw -Hill.

KOVÁCS, Ilona (2006), "Novas formas de organização do trabalho e autonomia no trabalho", Sociologia, Problemas e Práticas, n.․ 52, 41 -61.

TANNER, Daniel \& TANNER, Laurel N. (1980), Curriculum Development: Theory into practice. Nova Iorque, Macmillan.

TANNER, Daniel \& TANNER, Laurel N. (1987), Supervision in Education. Problems and practices, Nova Iorque, Macmillan.

WEICK, Karl E. (1995), Sensemaking in Organizations, Thousand Oaks, Sage Publications Series.

WRAGG, Edward. (1987), “Consulting and analysing interviews”, in J. Bell, et al. (eds), Conducting Small -Scale Investigations in Educational Management, London, Harper \& Row, 177 -197.

YIN, Robert (2005), Estudo de Caso: Planejamento e métodos, Porto Alegre, Bookman.

\section{NOTES}

1. A prestação de serviços é definida, na expressão "organização de serviços" de Peter M. Blau e Richard W. Scott (1977), da seguinte forma: "Uma organização de serviços é definida como uma organização cujo principal benefi ciário é a parte do público que tem com ela contacto directo, com quem e para quem seus membros trabalham - em resumo, uma organização cuja função básica é servir os seus clientes" (Blau \& Scott, 1977: 66 -67).

2. Cf. Lima (1994: 119), em particular a descrição do taylorismo nos tempos actuais.

3. Charles Perrow considera, por exemplo, que a história dos hospitais mentais demonstra que a falta de uma tecnologia viável foi muitas vezes responsável pelo estado precário destas instituições (Perrow, 1965: 913).

4. De acordo com E. Wragg, a expressão "amostra de oportunidade" consiste na escolha de uma amostra segundo uma lógica de conveniência do entrevistador (Wragg, 1987: 179). No nosso caso, pressupunha assegurar que os actores convenientes à amostra estivessem implicados no próprio processo de supervisão.

5. As siglas utilizadas neste ponto para as diferentes categorias de entrevistados são: Enf. (Enfermeiro); Est. (Estagiário); e Sup. (Supervisora).

\section{ABSTRACTS}

A apresentação do quadro teórico para a compreensão da supervisão de estágios em enfermagem e a articulação interorganizacional Escola e Hospital partiu do pressuposto de que seria fundamental a análise de algumas dimensões do "Hospital como organização" para se perceber a supervisão no contexto de trabalho hospitalar. Ao realizar-se esta análise pela voz dos actores 
entrevistados, pretendeu -se ver também que implicações tinham as suas opiniões no que diz respeito à supervisão. De facto, parece existir um certo isomorfi smo entre o "modelo de supervisão" e o "modelo de organização", pelo que se deduz, neste contexto, que a evolução da supervisão, assim como os valores implícitos e explícitos a ela associados, serão condicionados pela própria transformação na organização hospitalar.

This study focuses on guidelines and clinical nursing practice supervision as analyzer of the phenomenon of inter-organizational articulation School of Nursing and Hospital. The course of this investigation was to interlace between some changes in oversight of clinical practice supervi sion with some political and social changes in the organizations in the study - School of Nursing and Hospital -, establishing pertinent sociological relations between both. The presentation of the theoretical framework for understanding the stages of supervision and coordination in Nursing School and Hospital interorganizational assumed it would be essential to analysis of some dimensions of the "Hospital as an organization" to realize the supervision in the context of hospital work. When carrying out this analysis by the voice of the interviewees also wanted to see what implications they had their opinions when it came to supervision. In fact, it seems there is some isomorphism between the "model of supervision" and "organizational model" by which it follows, in this context that the evolution of supervision, as well as implicit and explicit values associated with it will depend on the transformation itself in the hospital organization.

L'étude, intitulée "La supervision des stages á l'école d'infirmières et l'articulation inter orga nisationnelle École et Hôpital" met l'accent sur les orientations et les pratiques de supervision de stage en École d'Infirmière, comme analyseur de phénomènes d'Articulation Interorganisationnelle École d'Infirmières et Hôpital. La présentation du cadre théorique pour com prendre la supervision de stage á l'école d'infirmières et l'articulation inter organisationnelle Ecole et Hôpital, a estimé qu'il était crucial pour l'analyse de certains aspects de "l'hôpital comme une organisation" comprendre la surveillance dans le cadre des activités hospitalières. Dans l'exercice de cette analyse, les acteurs interrogés voix (huit stagiaires, cinq infirmières, un super viseur) a été choisi pour voir quelles sont les conséquences avaient aussi leurs représentations/ opinions, quand il s'agissait de la supervision. En fait, il semble qu'il y ait quelques isomorphisme entre le "modèle de supervision" et "modèle d'organisation" par laquelle émerge dans ce contexte que l'évolution du contrôle, ainsi que les valeurs implicites et explicites qui lui sont associés seront limités par la transformation très dans l'organisation des hôpitaux. L'étude de cas, du versant qualitatif et interprétatif, souligne ce point empirique où l'on peut apporter à la lecture croisée des données qui contextualiser toute la question de la supervision des stages.

\section{INDEX}

Mots-clés: stage organisations, École des sciences infirmières et l'hôpital, coordination interor ganisationelle, stages cadre de la surveillance en soins infirmiers

Keywords: clinical nursing practice supervision, interorganizational coordination, school and hospital organizations

Palavras-chave: organizações, escola de Enfermagem e Hospital, articulação

interorganizacional, contexto de supervisão de estágios 


\section{AUTHOR}

\section{ANA PAULA MACEDO}

Escola Superior de Enfermagem Calouste Gulbenkian, Universidade do Minho amacedo@ese.uminho.pt 